\title{
ОСОБЛИВОСТІ КОМОРБІДНОГО ПЕРЕБІГУ ЦУКРОВОГО ДІАБЕТУ 2 ТИПУ ТА ГІПОТИРЕОЗУ: ЛАБОРАТОРНІ ДАНІ
}

Вступ. Гіпотиреоз частіше розвивається у пацієнтів із цукровим діабетом 2 типу, ніж у загальній популяції. Це два найпоширеніших ендокринологічних розлади у світі. При коморбідності цукрового діабету 2 типу та гіпотиреозу частіше виникають макроваскулярні ускладнення, погіршується якість життя і збільшується смертність. Усе більше дослідників рекомендують рутинно досліджувати тиреоїдну функиію у хворих на цукровий діабет, що допоможе краще контролювати ці два стани.

Мета дослідження - оцінити лабораторні показники у хворих з поєднаним перебігом цукрового діабету 2 типу та гіпотиреозу і виявити можливі маркери їх коморбідного перебігу.

методи дослідження. Проведено ретроспективне дослідження медичної документації 538 хворих на цукровий діабет 2 типу, які перебували на лікуванні в ендокринологічному відділенні протягом 2019 p. Сорормовано 2 дослідних групи: 1-ша - 501 хворий на цукровий діабет 2 типу; 2-га - 37 пацієнтів з коморбідним перебігом цукрового діабету 2 типу та гіпотиреозу. Оцінювали лабораторні показники (результати загального аналізу крові, ліпідограми, гормони щитоподібної залози, біохімічні маркери) та здійснювали статистичну обробку за допомогою розрахунку медіани (Me), нижнього (Lq) і верхнього (Uq) квартилів, U-критерію Манна - Уітні.

Результати й обговорення. При дослідженні показників загального аналізу крові виявлено ймовірно нижчі показники гемоглобіну й еритроцитів у 2-й групі ( $p=<0,001$ і $p=0,043)$, швидкість осідання еритроцитів була на 15,4 \% більшою порівняно з 1-ю групою $(p=0,045)$. Показники глікозильованого гемоглобіну на 10,0\% вищі у 2-й групі (p=0,035) порівняно з 1-ю групою. Під час оцінювання ліпідограми виявлено вірогідні відмінності в показниках холестеролу ліпопротеїнів високої щільності, залишкового холестеролу, не холестеролу ліпопротеїнів високої щільності й триацилгліцеролів при порівнянні дослідних груп ( $p=0,01$, $p=0,004, p=0,008, p=0,047)$.

Висновки. У пацієнтів з поєднаним перебігом иукрового діабету 2 типу та гіпотиреозу виявляють нижчі значення гемоглобіну й еритроцитів, вірогідно вищі рівні швидкості осідання еритроцитів, глікозильованого гемоглобіну, а також у них прогресує дисліпідемія за рахунок холестеролу ліпопротеїнів високої щільності, не холестеролу ліпопротеїнів високої щільності, залишкового холестеролу і триацилгліцеролів порівняно з хворими на цукровий діабет 2 типу.

КЛЮчОВІ СЛОВА: цукровий діабет 2 типу; гіпотиреоз; лабораторні дані.

ВСТУП. Діабет - одна з найважливішихпроблем охорони здоров'я сьогодення. У світі зареєстровано близько мільярда людей, хворих на діабет. 3 них основну частку (близько $90 \%$ ) становлять пацієнти із цукровим діабетом 2 типу (ЦД2) [1]. Загалом захворюваність на діабет 2 типу постійно зростає в усіх регіонах планети. Це може бути пов'язано зі збільшенням урбанізації, індустріалізацією, старінням населення, що призводить до більш сидячого способу життя, споживання шкідливої їжі та, як наслідок, ожиріння. Цукровий діабет 2 типу також часто реєструють серед підлітків та молодих людей [1].

Диссуннкція щитоподібної залози (ЩЗ) після цукрового діабетує другою найбільш поширеною метаболічною дисфрункцією у світі [2]. Вона може (c) В. А. Мусієнко, М. І. Марущак, 2021. проявлятися кількома шляхами - при збільшеному синтезі тиреоїдних гормонів розвивається гіпертиреоз, зменшення ж призводить до гіпотиреозу, при збільшенні залози в розмірах виникає дисрузний або вузловий зоб, також може перебігати безсимптомно у вигляді субклінічного гіпо- чи гіпертиреозу [3]. Розповсюдженість диссункції щитоподібної залози залежить від віку, статі, расової приналежності, а також географрічно залежить від того, скільки йоду споживає населення [4].

В останні роки науковці все більше уваги приділяють хворим з поєднаним перебігом цукрового діабету 2 типу та диссрункцією щитоподібної залози. Ці захворювання можуть впливати одне на одне різними шляхами. Диссрункція щ3 виникає у хворих на цукровий діабет 2 типу 
частіше, ніж у загальній популяції [5-7]. У ряді робіт повідомляється про її поширеність серед хворих на цукровий діабет у межах від 2,2 до $17,0 \%[8,9]$.

Хворі на цукровий діабет 2 типу частіше хворіють на первинний гіпотиреоз (ГТ) і мають вищі рівні вільного трийодтироніну та тиреотропного гормону (ТТГ) порівняно з еутиреоїдними особами [10].

У регіонах з достатнім споживанням йоду поширеність первинного ГТ становить від 1 до $2 \%$. При цьому жінки хворіють у 10 разів частіше, ніж чоловіки [11]. 3 іншого боку, у хворих на ЦД2, за оцінкою різних авторів, поширеність ГТ коливається від 5,7 до 37,1 \% [12-14]. Захворюваність на субклінічний гіпотиреоз у пацієнтів із ЦД2 також активно вивчають, і вона становить від 2,2 до $17,0 \%[15,16]$.

Мета дослідження - оцінити лабораторні показники у хворих з поєднаним перебігом цукрового діабету 2 типу та гіпотиреозу і виявити можливі маркери їх коморбідного перебігу.

МЕТОДИ ДОСЛІДЖЕННЯ. 3 метою ретроспективного аналізу медичної документації в дослідження включили 538 пацієнтів із цукровим діабетом 2 типу, які перебували на стаціонарному лікуванні в ендокринологічному відділенні комунального некомерційного підприємства “Тернопільська університетська лікарня" Тернопільської обласної ради протягом 2019 р. Хворих поділили на 2 групи: 1-ша - 501 хворий на Цд2 без супутньої дисорункції щ3; 2-га - 37 пацієнтів з коморбідним перебігом ЦД2 і гТ.

Діагноз ЦД2 було встановлено згідно з рекомендаціями Американської асоціації діабету. Діагностичним критерієм слугував глікозильований гемоглобін, рівень якого становив $\geq 6,5 \%$ [17].

Гіпотиреоз діагностували відповідно до критеріїв Європейської тиреоїдної асоціації: підвищення рівня тиреотропного гормону в поєднанні зі зниженням рівня тироксину $\left(\mathrm{T}_{4}\right)$ [18]. Якщо значення $\mathrm{T}_{4}$ були в межах норми, встановлювали субклінічний гіпотиреоз.

3 дослідження було виключено пацієнтів, які мали в анамнезі гіпертиреоз чи інші захворювання щитоподібної залози (крім гіпотиреозу), приймали на момент дослідження препарати, що впливають на рівень гормонів щитоподібної залози, вагітних чи жінок у період лактації, пацієнтів 3 онкологічними захворюваннями.

Показники загального аналізу крові визначали на автоматичному гематологічному аналізаторі “Yumizen H500 СТ", рівень інсуліну в крові на імунофрерментному аналізаторі "Thermo Scientific Multiskan FC", концентрацію глюкози, активність аланінамінотрансорерази (АлАТ) і аспартатамінотрансорерази (АсАТ) - за допомогою стандартних наборів на автоматичному біохімічному аналізаторі "COBAS INTEGRA® 400" ("Roche Diagnostics").

Показники ліпідного профрілю сироватки крові визначали в лабораторії Тернопільської університетської лікарні. Концентрацію загального холестеролу (ЗХС), триацилгліцеролів (ТГ), холестеролу ліпопротеїнів високої щільності (XC лПВщ) визначали за допомогою комерційно доступних наборів на аналізаторі "COBAS 6000" ("Roche Hitachi", Німеччина).

Якщо рівень триацилгліцеролів <4,5 ммоль/л, концентрацію холестеролу ліпопротеїнів низької щільності (ХС ЛПНЩ) вираховували за фрормулою Фрідевальда:

ХС ЛПНЩ (ммоль/л)=3ХС-ХС лПВЩ-(ТГ×0,45).

Не ХС ЛПВЩ визначали за такою фрормулою (якщо рівень ТГ >4,5 ммоль/л):

Не ХС лпВЩ=3ХС-ХС лПВщ.

Залишковий холестерол вираховували, використовуючи фоормулу:

Залишковий XС (ммоль/л)= =3ХС-(XС ЛПВЩ+ХС ЛПНЩ).

Середній вік пацієнтів - 56 років. Гендерний розподіл у групі ЦД2 був таким: 274 особи чоловічої статі, що становило 54,7 \%, 227 осіб жіночої статі, що становило 45,3 \% відповідно. У групі ЦД2+ГТ чоловіків було 4 (10,8 \%), жінок - 33 $(89,2$ \%). Індекс маси тіла (кг/м²) у групі Цд2+ГТ складав 31,6, що вірогідно не відрізнялося від даних 1-ї групи (IMT=30,5).

Вибір методу статистичного дослідження базувався на правильності розподілу досліджуваних ознак.

Зважаючи на неправильний розподіл кількісних характеристик, їх описову статистику здійснювали у вигляді розрахунку медіани (Ме), нижнього (Lq) і верхнього (Uq) квартилів. Попарне порівняння груп проводили з використанням U-критерію Манна - Уїтні при оцінюванні рівня статистичної значущості.

РЕЗУЛЬТАТИЙ ОБГОВОРЕННЯ. При аналізі показників загального аналізу крові (табл. 1) було виявлено статистично значущу відмінність між значеннями гемоглобіну $(p=<0,001)$ й еритроцитів ( $p=0,043)$, у групі ЦД2 середні значення були на 8,7 та 5,5 \% вищими, ніж у групі ЦД2+ГТ відповідно. Швидкість осідання еритроцитів (ШОЕ) у групі ЦД2 була меншою на 15,4 \% порівняно з групою ЦД2+ГТ, що також статистично достовірно ( $p=0,045)$.

При дослідженні показників лейкограми (рис. 1) отримали такі дані: показник лейкоцитів у групі ЦД2 - 6,4 (5,2; 7,6) Г/л, у групі ЦД2+ГТ - 
Таблиця 1 - Показники загального аналізу крові у пацієнтів з коморбідним перебігом цукрового діабету 2 типу та гіпотиреозу стосовно хворих на цукровий діабет 2 типу

\begin{tabular}{||l|c|c|c|c||}
\hline $\begin{array}{c}\text { Група } \\
\text { хворих }\end{array}$ & Гемоглобін, г/л & $\begin{array}{c}\text { Еритроцити, } \\
10^{12}\end{array}$ & $\begin{array}{c}\text { Кольоровий } \\
\text { показник }\end{array}$ & ШОЕ, мм/год \\
\hline ЦД2 & $138(127 ; 149)$ & $4,4(4 ; 4,7)$ & $0,9(0,9 ; 1)$ & $11(6 ; 20)$ \\
\hline ЦД2+ГТ & $126(116 ; 139)$ & $4,2(4,0 ; 4,55)$ & $0,9(0,9 ; 1)$ & $13(10 ; 22)$ \\
\hline $\mathrm{p}$ & $<0,001$ & $=0,04281$ & $=0,4883$ & $=0,0447$ \\
\hline
\end{tabular}

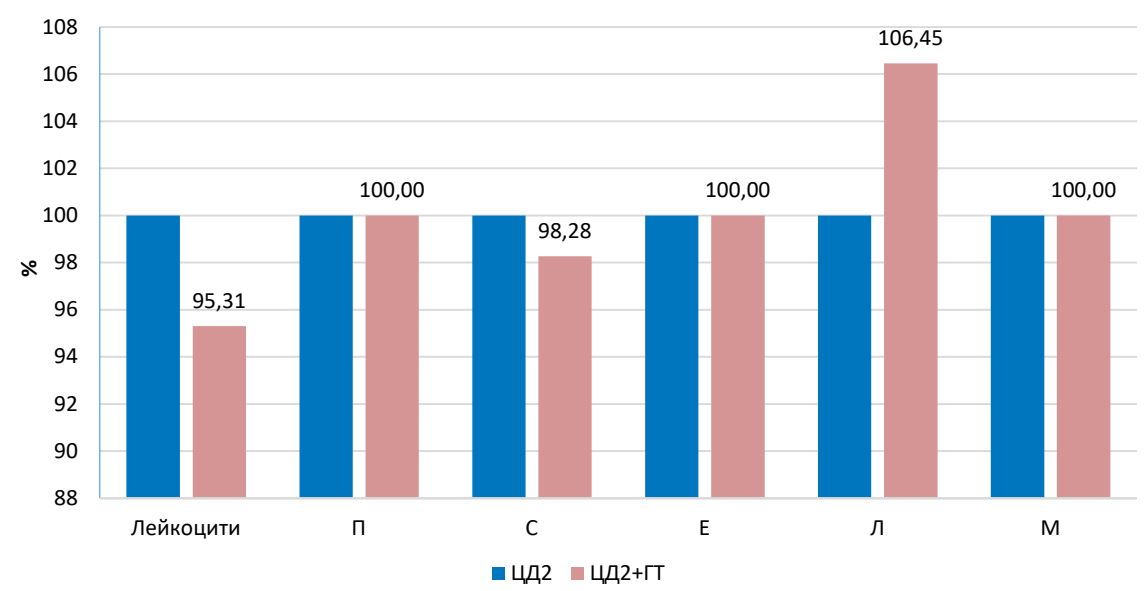

Рис. 1. Зіставлення (\%) показників лейкограми у пацієнтів з коморбідним перебігом цукрового діабету 2 типу та гіпотиреозу стосовно даних хворих на цукровий діабет 2 типу (П - паличкоядерні нейтрофріли, С - сегментоядерні нейтрофріли, Е - еозинофріли, Л - лімфоцити, М - моноцити).

$6,1(4,87 ; 7,67)$ Г/л ( $\mathrm{p}=0,6686)$ відповідно, паличкоядерні нейтрофріли - $5(3 ; 7) \%$ та $5(4 ; 6) \%$ $(\mathrm{p}=0,3735)$, сегментоядерні нейтрофріли $-58(50 ;$ 64) \% і $57(53 ; 63) \%(p=0,5778)$, еозинофіли $1(1 ; 3) \%$ та $1(1 ; 2) \%(p=0,8181)$, лімфоцити $31(25 ; 39) \%$ i $33(25 ; 39) \%$ (p=0,687), моноцити - $3(1 ; 5) \%$ та $3(2 ; 6,05) \%(p=0,4493)$. Статистичної вірогідності між дослідними групами не було виявлено.

Отже, отримані дані вказують на зниження рівнів гемоглобіну й еритроцитів у пацієнтів 3 поєднаним перебігом цукрового діабету 2 типу та гіпотиреозу порівняно з хворими лише на Цд2. Це узгоджується з даними інших дослідників, зокрема, в A. Nair та ін. [19] 26 \% пацієнтів 3 коморбідним перебігом ЦД2 і диссрункцією щЗ мали анемію, а в А. H. Khassawneh та ін. [20] майже половина хворих (47\%).

При оцінюванні показників вуглеводного обміну (табл. 2) встановлено, що вміст глікозильованого гемоглобіну в групі ЦД2+ГТ вірогідно вищий, порівняно 3 групою ЦД2, на $10 \%$ $(p=0,035)$. У показниках глікемії натще, інсуліну та індексу HOMA-IR імовірних відмінностей між групами не було виявлено. Рівень глікозильованого гемоглобіну $>7 \%$ як предиктор розвитку тиреоїдної диссрункції у пацієнтів із ЦД2 виділяють чимало науковців $[3,7,14]$.

Встановлено, що в групі Цд2 показник залишкового ХC на 29,2 \% вірогідно нижчий $(p=0,004)$ порівняно з групою ЦД $2+\Gamma T$, не XС лПвЩ - на 12,9 \% ( $p=0,008)$, ТГ - на 27,7\% $(\mathrm{p}=0,048)$ відповідно (табл. 3). Рівень холестеролу ліпопротеїнів високої щільності у групі ЦД2 був вищим на $11 \%(p=0,01)$, ніж у групі Цд2+ГТ. Водночас показники 3ХС та ХС ЛПНЩ у дослідних групах статистично не відрізнялись. У кроссекційному дослідженні E. H. Elgazar та ін. [7] спостерігали значне підвищення рівнів триацилгліцеролів і загального холестеролу в пацієнтів із ЦД2 та диссрункцією ЩЗ порівняно з хворими на ЦД2. W. Du та iн. [10] виділяють низький рівень ХС ЛПВЩ у хворих на ЦД2 як фрактор ризику розвитку диссрункції щитоподібної залози.

При міжгруповому порівнянні гормонів щитоподібної залози (табл. 4) отримано вірогідно

Таблиця 2 - Показники вуглеводного обміну в пацієнтів 3 коморбідним перебігом цукрового діабету 2 типу та гіпотиреозу порівняно з хворими на цукровий діабет 2 типу

\begin{tabular}{||l|c|c|c|c||}
\hline $\begin{array}{c}\text { Група } \\
\text { хворих }\end{array}$ & $\begin{array}{c}\text { Глікемія натще, } \\
\text { ммоль/л }\end{array}$ & $\begin{array}{c}\text { Глікозильований } \\
\text { гемоглобін, \% }\end{array}$ & $\begin{array}{c}\text { Інсулін, } \\
\text { мМО/мл }\end{array}$ & Індекс HOMА-IR \\
\hline ЦД2 & $9,4(7,5 ; 12,1)$ & $8,1(6,99 ; 9,3)$ & $13,85(9,87 ; 17,34)$ & $5,59(4,58 ; 6,87)$ \\
\hline ЦД2+ГТ & $9,92(8,04 ; 12,4)$ & $9(7,47 ; 10)$ & $14,32(10,25 ; 17,15)$ & $6,09(4,52 ; 7,71)$ \\
\hline $\mathrm{p}$ & $=0,5558$ & $=0,03477$ & $=0,6823$ & $=0,2508$ \\
\hline
\end{tabular}


Таблиця 3 - Показники ліпідограми у пацієнтів з коморбідним перебігом

цукрового діабету 2 типу та гіпотиреозу порівняно з хворими на цукровий діабет 2 типу

\begin{tabular}{||c|c|c|c|c|c|c||}
\hline $\begin{array}{c}\text { Група } \\
\text { хорих }\end{array}$ & ЗХС, ммоль/л & $\begin{array}{c}\text { ХС ЛПВЩ, } \\
\text { ммоль/л }\end{array}$ & $\begin{array}{c}\text { ХС ЛПНЩ, } \\
\text { ммоль/л }\end{array}$ & $\begin{array}{c}\text { Залишковий } \\
\text { ХС, ммоль/л }\end{array}$ & $\begin{array}{c}\text { Не ХС ЛПВЩ, } \\
\text { ммоль/л }\end{array}$ & ТГ, ммоль/л \\
\hline ЦД2 & 4,99 & 1,1 & 3,05 & 0,75 & 3,92 & 1,83 \\
& $(4,28 ; 5,88)$ & $(0,95 ; 1,24)$ & $(2,4 ; 3,9)$ & $(0,44 ; 1,18)$ & $(3,21 ; 4,68)$ & $(1,09 ; 2,82)$ \\
\hline ЦД2+ГТ & 5,28 & 0,98 & 3,34 & 1,06 & 4,5 & 2,53 \\
& $(4,8 ; 5,96)$ & $(0,82 ; 1,17)$ & $(2,64 ; 3,91)$ & $(0,72 ; 1,29)$ & $(3,74 ; 4,88)$ & $(1,9 ; 2,92)$ \\
\hline $\mathrm{p}$ & $=0,06821$ & $=0,01028$ & $=0,1403$ & $=0,004275$ & $=0,008235$ & $=0,04736$ \\
\hline
\end{tabular}

Таблиця 4 - Показники рівня гормонів щитоподібної залози у хворих на цукровий діабет 2 типу з коморбідним гіпотиреозом порівняно з пацієтами із цукровим діабетом 2 типу

\begin{tabular}{||l|c|c|}
\hline \multicolumn{1}{|c|}{ Група хворих } & ТТГ, мкМО/мЛ & $\mathrm{T}_{4}$, пмоль/л \\
\hline ЦД2 & $1,94(1,57 ; 2,84)$ & $16,04(14,95 ; 17,23)$ \\
\hline ЦД2+ГТ & $4,56(2,53 ; 8,37)$ & $9,91(8,82 ; 12,64)$ \\
\hline $\mathrm{p}$ & $<0,001$ & $<0,001$ \\
\hline
\end{tabular}

нижчі на 57,5 \% показники ТТГ у групі хворих на ЦД2 порівняно з групою ЦД2+ГТ ( $p=<0,001)$ та вірогідно вищі на 38,2 \% показники $\mathrm{T}_{4}(\mathrm{p}=<0,001)$ відповідно. Результати вивчення тиреоїдної фрункції в інших дослідженнях показують вищі рівні ТТГ і Т 4 у пацієнтів з коморбідним перебігом ЦД2 та дисфункцією щЗ порівняно 3 хворими на ЦД2 [7, 12].

При дослідженні лабораторних показників у хворих (рис. 2) виявлено тенденцію до їх зниження: АсАТ у групі ЦД2 - 18,1 $(14,2 ; 25,8)$ Од/л порівняно з групою ЦД2+ГП- $23(15,5 ; 30,3)$ Од/л ( $p=0,077)$, АлАТ - 19,9 (14; 29,6) Од/л і 22 (13,3; $32,1)$ Од/л ( $p=0,445)$, загального білірубіну - 9 $(6 ; 13,6)$ мкмоль/л та 8,7 (5,6; 11) мкмоль/л $(\mathrm{p}=0,44)$, загальної амілази - $44(34 ; 66)$ Од/л і $38(31 ; 55)$ Од/л ( $p=0,399)$, загального протеїну $71,1(67,6 ; 75)$ г/л та 71,4 (68; 75,3) г/л (p=0,608), креатиніну - 71 (60; 85) мкмоль/л і 66 (58; 77) мкмоль/л ( $p=0,253)$, сечовини - 5,4 $(4,3 ; 6,8)$ ммоль/л та 5,7 $(4,4 ; 6,6)$ ммоль/л $(p=0,652)$ відповідно.

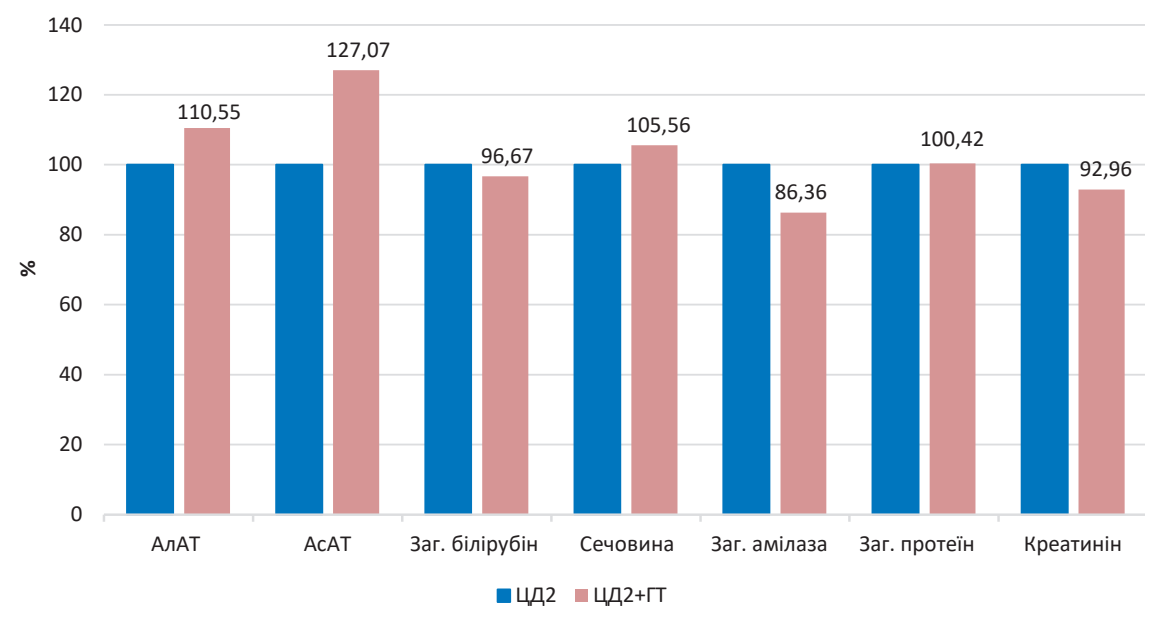

Рис. 2. Зіставлення (\%) показників біохімічного аналізу крові у пацієнтів з коморбідним перебігом цукрового діабету 2 типу та гіпотиреозу стосовно даних хворих на цукровий діабет 2 типу.

ВИСНОВКИ. У пацієнтів з поєднаним перебігом цукрового діабету 2 типу та гіпотиреозу виявляють нижчі значення гемоглобіну $(p=<0,001)$ й еритроцитів ( $p=0,043)$, вірогідно вищі рівні швидкості осідання еритроцитів ( $p=0,047)$, глікозильованого гемоглобіну (на 10,0 \%), а також у них прогресує дисліпідемія за рахунок холестеролу ліпопротеїнів високої щільності, не холестеролу ліпопротеїнів високої щільності, залишкового холестеролу і триацилгліцеролів порівняно 3 хворими на цукровий діабет 2 типу. 


\section{СПИСОК ЛІТЕРАТУРИ}

1. IDF Diabetes Atlas: Global estimates of diabetes prevalence for 2017 and projections for 2045 / N. H. Cho, J. E. Shaw, S. Karuranga [et al.] // Diabetes Res. Clin. Pract. - 2018. - 138. - P. 271-281.

2. Investigating the prevalence of primary thyroid dysfunction in obese and overweight individuals: Tehran thyroid study / M. Mahdavi, A. Amouzegar, L. Mehran [et al.] // BMC Endocr Disord. - 2021. -21, No. 1. - P. 89.

3. Ogbonna S. U. Risk factors of thyroid dysfunction in patients with type 2 diabetes mellitus / S. U. Ogbonna, I. U. Ezeani // Front Endocrinol. (Lausanne). - 2019. 10. - P. 440.

4. Prevalence and risk factors of thyroid dysfunction in older adults in the community / N. Diab, N. R. Daya, S. P. Juraschek [et al.] // Sci. Rep. - 2019. - 9, No. 1. P. 13156.

5. Elmenshawi I. M. Prevalence of thyroid dysfunction in diabetic patients / I. M. Elmenshawi // Journal of Diabetes, Metabolic Disorders \& Control. -2017. - 4, No. 2.

6. Prevalence of thyroid dysfunction among type 2 diabetes mellitus patients / M. V. Jali, S. Kambar, S. M. Jali [et al.] // Diabetes Metab. Syndr. - 2017. - 11, Suppl. 1. P. S105-S108.

7. Thyroid dysfunction prevalence and relation to glycemic control in patients with type 2 diabetes mellitus / E. H. Elgazar, N. E. Esheba, S. A. Shalaby, W. F. Mohamed // Diabetes Metab. Syndr. - 2019. - 13, No. 4. P. 2513-2517.

8. Subclinical hypothyroidism and type 2 diabetes: A systematic review and meta-analysis / C. Han, X. He, X. Xia [et al.] // PLoS One. - 2015. - 10, No. 8. P. e0135233.

9. Thyroid dysfunction in type 2 diabetes mellitus patients / I. Subekti, L. A. Pramono, E. Dewiasty, D. S. Harbuwono // Acta Med. Indones. - 2017. - 49, No. 4. - P. 314-323.

10. Prevalence of thyroid disorders and associated risk factors with various glycemic status in North China / W. Du, F. Wang, M. Zhao [et al.] // Biotechnology \& Biotechnological Equipment. - 2019. - 33, No. 1. P. 1244-1250.

\section{REFERENCES}

1. Cho, N.H., Shaw, J.E., Karuranga, S., Huang, Y., da Rocha Fernandes, J.D., Ohlrogge, A.W., \& Malanda, B. (2018). IDF Diabetes Atlas: Global estimates of diabetes prevalence for 2017 and projections for 2045. Diabetes Res. Clin. Pract., 138, 271-281. DOI:10.1016/j. diabres.2018.02.023

2. Mahdavi, M., Amouzegar, A., Mehran, L., Madreseh, E., Tohidi, M., \& Azizi, F. (2021). Investigating the prevalence of primary thyroid dysfunction in obese and overweight individuals: Tehran thyroid study. BMC Endocr. Disord., 21 (1), 89. DOI:10.1186/s12902-021-00743-4

3. Ogbonna, S.U., \& Ezeani, I.U. (2019). Risk factors of thyroid dysfunction in patients with type 2 diabetes mellitus. Front Endocrinol. (Lausanne), 10, 440. DOI:10.3389/fendo.2019.00440

4. Diab, N., Daya, N.R., Juraschek, S.P., Martin, S.S., McEvoy, J.W., Schultheiss, U.T., . . Selvin, E. (2019). Prevalence and risk factors of thyroid dysfunction in older adults in the community. Sci. Rep., 9 (1), 13156. DOI:10.1038/s41598-019-49540-z
11. Vanderpump P. J. Epidemiology of thyroid disease / P. J. Vanderpump // Encyclopedia of Endocrine Diseases, 2018. - P. 486-495.

12. Risk factors for thyroid dysfunction among type 2 diabetic patients in a highly diabetes mellitus prevalent society / M. Al-Geffari, N. A. Ahmad, A. H. Al-Sharqawi [et al.] // Int. J. Endocrinol. - 2013. - 2013. - P. 417920.

13. Talwalkar P. Prevalence of hypothyroidism in patients with type 2 diabetes mellitus and hypertension in India: a cross-sectional observational study / P. Talwalkar, V. Deshmukh, M. Bhole // Diabetes Metab. Syndr. Obes. - 2019. - 12. - P. 369-376.

14. Thyroid dysfunction among Greek patients with type 1 and type 2 diabetes mellitus as a disregarded comorbidity / M. E. Barmpari, M. Kokkorou, A. Micheli [et al.] // J. Diabetes Res. - 2017. - 2017. - P. 6505814.

15. Association of thyroid-stimulating hormone levels with microvascular complications in type 2 diabetes patients / Q. Qi, Q. M. Zhang, C. J. Li [et al.] // Med. Sci. Monit. - 2017. - 23. - P. 2715-2720.

16. Assessment of thyroid dysfunctions in type 2 diabetes mellitus patients in Surman, Western-Libya / A. A. Ahmed, S. Mohamed, S. A. Elmadi [et al.] // International Journal of Clinical and Experimental Medical Sciences. - 2017. - 3, No. 1. - P. 1-4.

17. A. American Diabetes. 10. Cardiovascular Disease and Risk Management: Standards of Medical Care in Diabetes-2019 // Diabetes Care. - 2019. - 42, Suppl. 1. - P. S103-S123.

18. Management of primary hypothyroidism: statement by the British Thyroid Association Executive Committee / O. Okosieme, J. Gilbert, P. Abraham [et al.] // Clin. Endocrinol. (Oxf.) - 2016. -84, No. 6. - P. 799-808.

19. Prevalence and associations of hypothyroidism in Indian patients with type 2 diabetes mellitus / A. Nair, C. Jayakumari, P. K. Jabbar [et al.] // J. Thyroid Res. 2018. - 2018. - P. 5386129

20. Prevalence and predictors of thyroid dysfunction among type 2 diabetic patients: A case-control study / A. H. Khassawneh, A. H. Al-Mistarehi, A. M. Zein Alaabdin [et al.] // Int. J. Gen. Med. - 2020. - 13. - P. 803-816.

5. Elmenshawi, I.M. (2017). Prevalence of thyroid dysfunction in diabetic patients. Journal of Diabetes, Metabolic Disorders \& Control, 4 (2). DOI:10.15406/ jdmdc.2017.04.00106

6. Jali, M.V., Kambar, S., Jali, S.M., Pawar, N., \& Nalawade, P. (2017). Prevalence of thyroid dysfunction among type 2 diabetes mellitus patients. Diabetes Metab. Syndr., 11 (1), S105-S108. DOI:10.1016/j.dsx.2016.12.017

7. Elgazar, E.H., Esheba, N.E., Shalaby, S.A., \& Mohamed, W.F. (2019). Thyroid dysfunction prevalence and relation to glycemic control in patients with type 2 diabetes mellitus. Diabetes Metab. Syndr., 13 (4), 25132517. DOI:10.1016/j.dsx.2019.07.020

8. Han, C., He, X., Xia, X., Li, Y., Shi, X., Shan, Z., \& Teng, W. (2015). Subclinical hypothyroidism and type 2 diabetes: Asystematic review and meta-analysis. PLOS One, 10 (8), e0135233. DOI:10.1371/journal.pone.0135233

9. Subekti, I., Pramono, L.A., Dewiasty, E., \& Harbuwono, D.S. (2017). Thyroid dysfunction in type 2 diabetes mellitus patients. Acta Med. Indones, 49 (4), 314-323. 
10. Du, W., Wang, F., Zhao, M., Zhang, H., Zhang, X., Zhao, J., \& Gao, L. (2019). Prevalence of thyroid disorders and associated risk factors with various glycemic status in North China. Biotechnology \& Biotechnological Equipment, 33 (1), 1244-1250. DOI:10.1080/13102818. 2019.1656106

11. Vanderpump, M.P.J. (2018). Epidemiology of thyroid disease. In Encyclopedia of Endocrine Diseases (pp. 486-495).

12. Al-Geffari, M., Ahmad, N.A., Al-Sharqawi, A.H., Youssef, A.M., Alnaqeb, D., \& Al-Rubeaan, K. (2013). Risk factors for thyroid dysfunction among type 2 diabetic patients in a highly diabetes mellitus prevalent society Int. J. Endocrinol., 2013, 417920. DOI:10.1155/2013/417920

13. Talwalkar, P., Deshmukh, V., \& Bhole, M. (2019). Prevalence of hypothyroidism in patients with type 2 diabetes mellitus and hypertension in India: a cross-sectional observational study. Diabetes Metab. Syndr. Obes. 12, 369-376. DOI:10.2147/DMSO.S181470

14. Barmpari, M.E., Kokkorou, M., Micheli, A., Alexiou, I., Spanou, E., Noutsou, M., \& Thanopoulou, A. (2017). Thyroid dysfunction among Greek patients with type 1 and type 2 diabetes mellitus as a disregarded comorbidity. J. Diabetes Res., 2017, 6505814. doi:10.1155/2017/6505814

15. Qi, Q., Zhang, Q.M., Li, C.J., Dong, R.N., Li, J.J., Shi, J.Y., . . Zhang, J.Y. (2017). Association of thyroidstimulating hormone levels with microvascular complica- tions in type 2 diabetes patients. Med. Sci. Monit., 23, 2715-2720. DOI:10.12659/msm.902006

16. Ahmed, A.A., Mohamed, S., Elmadi, S.A., Abdorabo, A.A., Ismail, I.M., \& Ismail, A.M. (2017). Assessment of thyroid dysfunctions in type 2 diabetes mellitus patients in Surman, Western-Libya. International Journal of Clinical and Experimental Medical Sciences, 3 (1), 1-4. DOI:10.11648/j.ijcems.20170301.11

17. American Diabetes, A. (2019). 10. Cardiovascular Disease and Risk Management: Standards of Medical Care in Diabetes-2019. Diabetes Care, 42 (Suppl. 1), S103-S123. DOI:10.2337/dc19-S010

18. Okosieme, O., Gilbert, J., Abraham, P., Boelaert, K., Dayan, C., Gurnell, M., ... Vanderpump, M. (2016). Management of primary hypothyroidism: statement by the British Thyroid Association Executive Committee. Clin. Endocrinol. (Oxf), 84 (6), 799-808. DOI:10.1111/cen.12824

19. Nair, A., Jayakumari, C., Jabbar, P K., Jayakumar, R.V., Raizada, N., Gopi, A., . . Seena, T.P. (2018). Prevalence and associations of hypothyroidism in Indian patients with type 2 diabetes mellitus. J. Thyroid Res., 2018, 5386129. doi:10.1155/2018/5386129

20. Khassawneh, A.H., Al-Mistarehi, A.H., Zein Alaabdin, A.M., Khasawneh, L., AlQuran, T.M., Kheirallah, K.A., ... Obeidat, N. (2020). Prevalence and predictors of thyroid dysfunction among type 2 diabetic patients: A case-control study. Int. J. Gen. Med., 13, 803-816. DOI:10.2147/IJGM.S273900

\section{A. Musiienko, M. I. Marushchak}

\section{TYPE 2 DIABETES MELLITUS AND HYPOTHYROIDISM: LABORATORY DATA}

\section{Summary}

Introduction. Hypothyroidism is more common in patients with type 2 diabetes than in the general population. These are two most common endocrine disorders in the world. Comorbidity of type 2 diabetes and hypothyroidism will worsen macro-vascular complications, quality of life and mortality. More and more scientists recommend routine determination of thyroid hormone levels in patients with type 2 diabetes, which will help better control these two conditions.

The aim of the study - to evaluate laboratory parameters in patients with combined course of type 2 diabetes mellitus and hypothyroidism and to identify possible markers of their comorbid course.

Research Methods. A retrospective study of medical records of 538 patients with type 2 diabetes who were treated at the Endocrine Department of Ternopil University Hospital in 2019. Two experimental groups were formed: group 1 (501 patients with type 2 diabetes mellitus (T2DM)) and group 2 (37 patients with comorbid T2DM and hypothyroidism). Laboratory data were evaluated (results of general blood analysis, lipidograms, thyroid hormones, biochemical markers). Statistical analysis was performed by calculating the median (Me), lower (Lq) and upper (Uq) quartiles, Mann-Whitney U-test.

Results and Discussion. The study of general blood tests revealed probably lower $\mathrm{Hb}$ and RBC in group 2 $(p=<0.001$ and $p=0.043)$, the level of ESR was $15.4 \%$ higher than in group $1(p=0.045)$. HbA1c values were $10.0 \%$ higher in group $2(p=0.035)$ compared with group 1. Evaluating the lipid profile revealed significantly differences in HDL-C, RC, non-HDL-C and TG between experimental groups ( $p=0.01, p=0.004, p=0.008, p=0.047$ ).

Conclusions. Patients with comorbid type 2 diabetes mellitus and hypothyroidism have significantly lower values of hemoglobin and erythrocytes, significantly higher levels of ESR, HbA1c, and progressing dyslipidemia due to HDL-C, RC, non-HDL-C and TG compered to patients with type 2 diabetes mellitus only.

\section{KEY WORDS: type 2 diabetes mellitus; hypothyroidism; laboratory data.}

\footnotetext{
Адреса для листування: М. І. Марущак, Тернопільський національний медичний університет імені І. Я. Горбачевського мОз України, майдан Волі, 1, Тернопіль, 46001, Україна, e-mail: marushchak@tdmu.edu.ua.
} 